\title{
A simbologia dos números três e sete em contos maravilhosos'
}

\section{The symbolism of the numbers three and seven in fairy tales}

\author{
ARMINDO TEIXEIRA MESQUITA \\ Universidade de Trás-os-Montes e Alto Douro \\ Portugal \\ armesqui@utad.pt
}

Resumo. De todos os géneros da literatura popular, o conto é, sem dúvida, aquele que melhor se relaciona com o desenvolvimento cognitivo e socio-afetivo da criança, pois ajuda-a a vencer os problemas do crescimento e a encarar o mundo de forma mais natural. Por consequência, o conto maravilhoso teve, desde sempre, a grande finalidade de divertir, mas também, e sobretudo, de ensinar.

Daí a importância simbólica atribuída aos números três e sete que reenviam para conceitos como a perfeição e a totalidade, assumindo um papel central na compreensão das nossas ações. Tanto a magia do número três como a plenitude do número sete influenciam profundamente $\circ$ pensamento ocidental, sendo, por isso, natural a sua presença nas manifestações artísticas do povo, de onde provém os contos de fadas.

Palavras-chave: simbologia; número; três; sete; conto.
Abstract. Of all the genres of popular literature, the tale is certainly the one that has come to be best associated with cognitive and socio-emotional development of the child, because it helps the child to deal with the problems of growing up, and to face the world in a more natural way. Consequently, the fairy tale has always had the great objective to entertain, but also, and above all, to teach.

Thus the symbolic importance of the numbers three and seven, which convey concepts like perfection and wholeness, assume a central role in understanding our actions. Both the magic of the number three and the fullness of the number seven deeply affect Western thought, and so are naturally present in people's art, from which comes from fairy tales.

Key words: symbolism; number; three; seven; tale.

\footnotetext{
I Para citar este artículo: Mesquita, Armindo Teixeira (20I2). A simbologia dos números três e sete em contos maravilhosos. Alabe 6. [www.revistaalabe.com]

(Recibido O2-O3-2OI2; aceptado 23-O9-2OI2)
} 
Há maior significado escondido nos contos de fadas que me contaram na infância do que na verdade que a vida ensina.

Schiller

\section{Introdução}

De todos os géneros da literatura oral tradicional, o conto, ao sintetizar «formas de identificação cultural que perduram no imaginário e nas conceções mentais de quem os leu ou ouviu (Morgado e Pires, 20I2: Alabe 5), é, sem dúvida, aquele que melhor se relaciona com o desenvolvimento cognitivo e socio-afetivo da criança, pois ajuda-a a vencer os problemas do crescimento e a encarar o mundo de forma mais natural. Por consequência, o conto de fadas teve, desde sempre, a grande finalidade de divertir, mas também, e sobretudo, de ensinar / moralizar. Mesmo na sociedade de hoje, que caminha para a globalização com a grande evolução das novas tecnologias, os contos não podem ser postos de parte, tendo-se mesmo assistido a um grande esforço, no sentido de revitalizar as raízes populares. Daí a proliferação de reedições de textos de Perrault, dos Grimm, de Andersen ou Teófilo Braga, entre outros.

Este facto relaciona-se com a constante necessidade de,em qualquer momento ou lugar, as crianças terem modelos para construir a sua personalidadee a literatura para a infância ser «um dos elementos fundamentais na formação do sujeito» (Pires, 2OIO: Álabe 1). Na verdade, a psicologia atual demonstra que a mundividência infantil continua a estar ligada à dos contos de fadas, e continua a acreditar-se que a melhor educação é aquela que surge implicitamente, adequando-se a cada faixa etária e não necessitando de extensas e, por vezes, complexas explicações racionais.

Mas, então, porque é que o conto se mantém desde sempre tão importante para as crianças? De que modo ele consegue cativar as suas mentes ávidas? A resposta a estas questões prende-se a muitas reflexões, todas elas direcionadas para a linguagem simbólica em que os contos nos falam. De facto, estes afastam-se da realidade do quotidiano, para entrarem no mundo do faz de conta, cheio de duplos sentidos, em que nada é o que parece. Não cortam com a realidade, mas jogam com ela, enchendo-a de símbolos que ajudam no crescimento dos mais jovens.

\section{A linguagem simbólica dos números três e sete}

Os contos de fadas tocam profundamente os mais jovens, sobretudo pelo facto de se exprimirem numa linguagem próxima da deles, cheia de imagens e duplos sentidos, facilitando a adesão e fomentando o sonho e a fantasia. Como refere Bruno Bettelheim (I998), qualquer criança familiarizada com os contos maravilhosos reconhece que estes 
se lhe dirigem numa linguagem altamente simbólica, diferente da usada no dia a dia. É por isso que situações potencialmente reais se tornam importantes, pelo sentido simbólico que a criança capta. Este estudioso retoma o próprio Tolkien, que afirma que a verdade de um conto está na nossa imaginação: «Os contos de fadas não se preocupam evidente e primariamente com o que é possível, mas com o que é desejável» (Bettelheim, I998:I5I).

Assim, é fácil perceber que uma composição deste género esteja recheada de palavras, situações e alusões simbólicas. A simbologia dos números, por exemplo, é uma constante neste tipo de texto, surgindo com as mais variadas significações. Será por acaso que o herói do conto é, quase sempre, o mais jovem, o terceiro ou sétimo filho? Poderemos acreditar que o facto dos anões da Branca de Neve serem sete é apenas coincidência? É claroque, nestas histórias, nenhum número surge por acaso. E, dado o extenso domínio de um estudo deste género, iremos, aqui, centrar-nos na análise dos números três e sete, demonstrando a sua ocorrência na nossa realidade e, depois, em alguns contos, portugueses e estrangeiros.

\section{I.- O número três}

Olhando à nossa volta, ficamos atónitos por verificar que o número três está presente um pouco por toda a parte, em quase todos os domínios da nossa existência, desde a religião, à ética eà sociedade, passando pela própria ação humana. Subsistem inúmeras vozes céticas que acreditam que a tríade não passa de uma invenção dos modernos, ansiosos por encontrar uma regra geral e de origem divina onde existem apenas coincidências. Opomo-nos a esta posição, recusando que tenha sido o acaso a colocar o número três em tantas manifestações. E, para demonstrar o seu cariz transcendental e perfeito, passaremos a apresentar algumas das atualizações simbólicas deste algarismo.

Assim, começando pelo domínio religioso, podemos considerar que esteve/está presente em diversas religiões e civilizações, quase desde o limiar da história humana. Vejamos, por exemplo, a mitologia greco-latina, em que são três os deuses que governam o universo: Zeus domina o céu e a terra; Poseídon controla os oceanos e Hades vive nos infernos. Na tradição iraniana, o três domina a religião e a vida quotidiana, que devem ser regidas por três grandes preceitos: «Bom pensamento, boa palavra e boa acção» (Chevalier e Gheerbrant, I998: 973).

Nas religiões mais próximas de nós, esta tríade mantém-se. Na verdade, para o budismo, tudo é triplo: o tempo divide-se em passado, presente e futuro; o mundo contém a terra, a atmosfera e o céu; a própria manifestação divina é tripartida, com Brahma, Vishnu e Shiva. Os chineses também defendem a perfeição e a totalidade deste numeral. Saliente-se, ainda, que a base teológica do cristianismo assenta na tríade da unidade divina. Como referem Chevalier e Gheerbrant (r998:972) «Deus é umaemtrêspessoas». Os reis magos, que adoraram o Menino Jesus, simbolizam as funções que o próprio Cristo desempenharia no mundo: ser rei, padre e profeta da nova religião. Também as virtudes teologais são três: fé, esperança e caridade, assim como os domínios da Ética. De facto, 
a mentira, o sarcasmo e a imprudência são apontados como a destruição do Homem. Do mesmo modo, a calúnia, o ódio e a insensibilidade condenam ao inferno, enquanto o pudor, a cortesia e o temor a Deus guiam a humanidade para o bem.

Não é só na religião que este número mágico ocorre, verificando-se a sua existência em muitos outros campos. Na verdade, a vida humana é tripartida, na sua essência, pois divide-se em vida material, racional e espiritual. As próprias sociedades antigas tinham uma composição em três partes: clero, nobreza e povo. A nossa vida insere-se num ciclo tripartido, ao qual não podemos escapar: nascimento, crescimento e morte. Sem esquecer que as investigações científicas provam a existência de muitas tríades no corpo humano, acreditando-se mesmo que o número em estudo é a base de todas as grandes funções do nosso organismo. Afinal, não podemos esquecer que a sabedoria popular acredita no poder mágico do número três, visto como universal, que une a ordem espiritual com a intelectual. É por isso que o ditado popular português é bastante claro: «Três é a conta que Deus fez!». E mesmo no Tarot, continua a verificar-se que este número simboliza a criação, a perfeição divina.

Podemos, pois, concluir que o numeral em causa surge como um símbolo cuja alçada é universal, estando presente na metafísica, em toda a ação do homem e na complexidade da natureza. Representa a síntese perfeita entre o homem, o céu e a terra. Daí quesurja, muitas vezes, nos contos de fadas, associado aos diferentes momentos do desenvolvimento humano e da consciência, mas sem nunca pôr de parte o seu cariz mágico e transcendente.

\section{2.- O número sete}

Mais ainda do que acontece com o número três, o sete é tido como um número divino, representando a intervenção transcendente em todas as coisas e ideias da nossa realidade. É por isso que, também aqui, é necessário referir diferentes domínios em que a simbologia deste número é inquestionável.

Começaremos, mais uma vez, pela religião, verificando a presença deste símbolo em todas as grandes civilizações, desde os tempos mais antigos. Para os egípcios, é um sinónimo de vida eterna, ligado a um ciclo completo, perfeito. Na maioria das tradições gregas e romanas, existem vestígios da referida perfeição. Da mesma forma, Buda é representado por sete emblemas diferentes, remetendo para a tão procurada totalidade. $\mathrm{O}$ islão considera-o também um número perfeito, pois tudo é dividido em grupos de sete elementos: para os islamitas, existem sete céus e sete terras, sete mares, sete portas do paraíso e sete divisões do inferno.

Então, é fácil deduzir que este numeral está extremamente presente na religião cristã, sendo inúmeras vezes usado, simbolicamente, nas Sagradas Escrituras. Assim, temos os sete sacramentos, os sete pecados capitais e as sete virtudes que se lhe opõem, o candelabro de sete braços, as sete vacas do sonho do faraó, as sete trompetas do apocalipse. Foram sete os anos que Jacob trabalhou para ter direito à sua amada Raquel, e 
mais sete ainda antes de casar com ela. A construção do templo de Salomão demorou sete anos, da mesma forma que foram salvos do dilúvio sete casais de cada espécie, e que existem sete arcanjos diante do trono do Criador.

Na verdade, a essência simbólica do número sete deriva diretamente do poder divino, acreditando-se que representa a totalidade da vida moral, numa mistura de magia e sagrado. De facto, Deus criou o mundo em seis dias, reservando o sétimo ao descanso e ao culto. Retomando as palavras bíblicas, André Chardonnens (i990:5)afirma que «Dieu bénit le septième jour et le sanctifia, parce qu’en ce jour la, il s’était reposé de toute l'œuvre qu'il avait créée». O certo é que, desde as épocas mais antigas, a semana se divide em sete dias, aproximando-se dos sete dias da criação. Daí que o domingo seja, desde sempre, considerado «culto de Deus».

Vemos, pois, que o domínio religioso se dilui com o profano, que a perfeição do número sete foi alargada a diversas outras áreas. Podemos verificar, por exemplo, que a lua muda a cada sete dias, assim como cada rosa tem sete pétalas, de modo que Chevalier Gheerbrant (I998:860) defendem a existência de um simbolismo muito próprio neste número, direcionado para «uma mudanaça positiva». Quantas vezes olhamos maravilhados para o arco-íris, ou espetro solar, sem compreendermos racionalmente que a sua beleza se liga à conjugação perfeita das sete cores que o compõem? O mesmo acontece com as notas musicais: quantas vezes paramos para pensar que a sua perfeição advém do facto de serem sete? E não podemos esquecer que existem sete maravilhas no mundo, sete colinas em Roma e sete planetas sagrados da alquimia, numa época em que se conhecia pouco de astronomia e se considerava que o Sol, a Lua, Mercúrio, Vénus, Marte, Júpiter e Saturno eram todos planetas. Saliente-se também que, no tarot atual, o número sete assume-se como símbolo da manifestação superior, associando-se a vida e vibração. Além de que o cinema é considerado a sétima arte.

Na psicologia e nas ciências naturais existem alguns estudos cujo objetivo é provar a pertinência do número sete em toda a natureza e nas relações humanas. Assim, «dados da Psicologia mostram que a consciência não consegue lidar com mais de sete entidades...» (Soveral, 2003: 4). Quer isto dizer que qualquer problema, envolvendo unidades ou ideias em número superior a sete, terá de ser subdividido. Mesmo numa relação interpessoal, alcançamos cerca de sete características de outra pessoa, de cada vez. Com o tempo, captam-se mais, mas sempre em conjuntos de sete.

$\mathrm{Na}$ investigação científica, tem-se assistido a descobertas interessantes. Por exemplo, está provado que a renovação celular do corpo humano acontece de sete em sete anos, do mesmo modo que existem sete orifícios na cabeça de um homem normal. São ainda sete as etapas da evolução física e mental que se ligam aos sete estados da matéria e aos sete graus da consciência humana, tão bem representados pelos anões da Branca de Neve.

A título de curiosidade, poderemos mesmo acrescentar que, na Síria, existe um costume muito interessante que reenvia para a magia e cariz superior deste numeral: uma jovem sem pretendente deve afastar os maus-olhados com um banho de mar, em que sete vagas terão de lhe passar sobre a cabeça. 
Tudo que acabamos de ver permite-nos concluir que o número sete é «a chave do verdadeiro misticismo...» (Soveral, 2003:4), na medida em que se encontra na Bíblia, na história, na ciência, enfim, em todos os domínios da vida humana. Número mágico? Manifestação divina? Símbolo da totalidade e da perfeição? O certo é que este número se encontra em quase todo o lado, mostrando-nos imagens e sons que conduzem pelo tempo e pelo espaço numa tentativa de saber sempre mais sobre nós e sobre o mundo. É por isso que não acreditamos que a ocorrência tão frequente deste número, nos contos de fadas, seja simples coincidência.

\section{Os números très e sete em contos de fadas}

Como vimos anteriormente, os números três e sete estão presentes em inúmeros campos, reenviando-nos, repetidamente, para um simbolismo de magia e perfeição, intimamente ligado à intervenção divina. E os contos de fadas não escapam a estas manifestações, dado o cariz metafórico da sua linguagem, simples e direta, mas, simultaneamente, cheia de imagens e duplos sentidos, reenviando para as funções de divertimento e moralização / educação deste tipo de literatura.

Assim, este terceiro ponto será direcionado para o estudo das ocorrências destes símbolos em alguns contos maravilhosos, quer estrangeiros, quer portugueses. Como se trata de um domínio muito vasto, selecionámos alguns textos dos irmãos Grimm, de Perrault e de Teófilo Braga. Por questões de economia espacial, e para evitar repetições desnecessárias, o estudo será feito por autores, sendo, pois, apresentadas, em cada história, as ocorrências dos dois símbolos em simultâneo.

\section{I.- Em contos dos irmãos Grimm}

Nos contos dos dois irmãos alemães, a presença dos números é uma constante, sempre com simbologias ligadas ao desenvolvimento integral do ser humano e à intervenção da perfeição divina. Vejamos, pois, alguns exemplos desses símbolos.

Em «Os sete corvos», partimos da análise do título, para verificar a existência de uma associação imprevista, uma vez que temos o número sete, símbolo de perfeição, mas os corvos remetem para uma realidade disfórica, ligando-se ao mal e, por isso, opondo-se à beleza e ao positivismo do sete. Ao observarmos o desenrolar da sintagmática, apercebemo-nos do porquê desta associação. De facto, o casal tinha inicialmente sete filhos, o que mostra um ciclo completo, em que reina a harmonia. A chegada da filha mais nova, a oitava, vem quebrar a paz, uma vez que inicia um novo ciclo, levando à desgraça dos irmãos. A jovem passa anos sem conhecer a triste história, mas mal se apercebe do sucedido, decide partir para salvar os irmãos. Na verdade, só depois de passar por três tipos de astros: Sol, Lua e Estrelas chega ao local onde eles se encontram. Quer isto dizer que só através de um longo processo de maturação consegue compreender o que fazer para re- 
verter a tragédia. Já na montanha de cristal, vê-se confrontada com sete pratos e sete conjuntos de talheres, numa intertextualidade com os sete anões da Branca de Neve. Como estes, os sete corvos representam, mais uma vez, o amadurecimento humano, através do qual todos conseguirão a verdadeira felicidade.

No conto «As três fiandeiras», basta, mais uma vez, olhar para o título para se perceber a presença de um número mágico, neste caso o três, número universal da união com Deus, remetendo para a já referida perfeição. Após se encontrar no palácio, a jovem viu-se diante de tanto linho que passou três dias a chorar e, só depois da visita da rainha surgiu a tão preciosa ajuda. Temos aqui o número três como o limite entre o favorável e o desfavorável, dado que, depois deste acontecimento, a jovem já não teria qualquer desculpa para não iniciar o trabalho. É aqui que surgem as três mulheres de aspeto estranho para a auxiliarem. Estas senhoras representam três aspetos diferentes de uma mesma profissão, remetendo para um desdobramento que permite, à criança, compreender melhor o processo de maturação aqui evidenciado. A menina deveria ser capaz de fazer, sozinha, aquilo que as fiandeiras fazem juntas. Mas estas ajudam-na, com a condição de que não se envergonhe delas, o que poderá também simbolizar a vantagem da entreajuda, da camaradagem: se dividirmos as penas e as tarefas, tudo será mais fácil. Graças à inteligência e ao trabalho das fiandeiras, a jovem consegue casar com o príncipe e nunca mais precisa de fiar.

Já em «A rapariga dos gansos», os números em estudo começam a surgir no momento em que a mãe da princesa tem de despedir-se desta. De facto, antes de deixá-la partir, derrama três gotas do seu próprio sangue num lenço, afirmando que este a protegeria durante a longa jornada. Note-se que atribuiu um poder sobrenatural ao seu sangue, não sendo por acaso que caem exatamente três gotas. Além disso, é a partir do momento em que a jovem deixa cair o lenço ao rio que começa a delinear-se o seu calvário. Ao longo da viagem, são também três as coisas que a aia a obriga a fazer: dá-lhe o seu cavalo; despe as suas roupas luxuosas e jura que nunca revelará a verdade, sob pena de morte. Do mesmo modo, a jovem princesa vai três dias seguidos para o campo com os gansos, conversando com a cabeça de Falada e penteando os cabelos em trança, enquanto o companheiro corria atrás do chapéu, levado pelo vento. Só no terceiro dia, o rei toma conhecimento do segredo, remetendo, mais uma vez, para a simbologia do três como margem entre o favorável e o desfavorável. É no fim do terceiro dia que a sina da princesa se altera, sendo-lhe devolvido o seu lugar e castigando a falsa noiva, com a sentença que ela própria proferiu.

Logo na observação do título«Branca de Neve e os Sete Anões», temos a noção de que estamos perante números simbólicos. Assim, antes do nascimento da menina, a mãe de Branca de Neve picou-se no dedo e deixou cair três gotas de sangue na neve. É daí que virá, depois, o nome da jovem princesa. Saliente-se, também, que a menina se tornou a mais linda ao atingir a idade simbólica de sete anos, atingindo um estado de tal beleza e perfeição que enfureceu o coração ciumento da rainha, sua madrasta, que decide mesmo mandá-la matar. Perdida na floresta, deambula até encontrar uma pequena casinha, onde todos os utensílios são em número de sete, remetendo novamente para a 
harmonia e caráter transcendente do termo. Os próprios anões, também eles sete, funcionam como a metáfora do conhecimento humano. Seguindo as ideias do próprio Bruno Bettelheim (I998), cada um deles possui uma característica típica do comportamento do homem, tendo como única função preparar a jovem para a vida adulta. Quando a bruxa se desloca até à casa na floresta, tem de atravessar sete colinas, num intertexto com as colinas de Roma, muito tempo considerada uma cidade perfeita. Deve referir-se, ainda, que só à terceira tentativa a malvada madrasta consegue matar Branca de Neve, consumando a ideia popular de que «à terceira é de vez». Os próprios anões passam três dias a velar a jovem e, só aí se conformam com o sucedido.

A história de «Os seis cisnes» começa da mesma forma que muitas outras: um rei tinha seis filhos e uma filha, sendo esta a fechar o ciclo e, por isso, remetendo para a perfeição do número sete. É também por isso que ela é a escolhida, aquela que está destinada a grandes feitos, mas também a muitos sacrifícios. O seu caráter sagrado leva mesmo a que consiga escapar à terrível maldição da madrasta. Para salvar os irmãos das suas penas de cisne, aceita um grande sacrifício: não falar, nem rir durante seis anos e coser-lhes umas camisas com folhas de lírios, para que voltassem à forma humana. Uma vez quebrada a harmonia do número sete, é a mais jovem que tem de assegurar o restabelecimento da perfeição. A jovem irá, por sua vez, dar à luz três filhos, mais uma vez um número pleno. Mas só depois de ter passado por uma última humilhação - ser separada dos meninos e falsamente acusada pelo marido - consegue cumprir a penitência, contar a verdade e ser, finalmente, feliz.

Também na sintagmática do conto «A filha do moleiro», encontramos os números em estudo. A jovem depara-se com três grandes salas, cheias de palha, daí que sejam também três as vezes em que ela tem de recorrer ao anão, num esforço de crescimento pessoal e social, que exige uma recompensa. Na verdade, o anão não trabalha de forma desinteressada, exigindo, primeiro, um colar, depois um anel e, por fim, o primeiro filho da moleira. Num instante de desespero, ela aceita tudo, mas arrepende-se e acaba por celebrar um acordo com o anão: tem três dias para descobrir o nome deste, caso contrário, perderá realmente o seu herdeiro. E não é por coincidência que só no final do terceiro dia consegue desvendar o mistério. Trata-se, pois, da simbologia do três como um limite temporal entre o bem e o mal, o favorável e o desfavorável.

Por fim, em «João sem medo», deparamo-nos com um jovem que afirma não ter medo de nada, daí que a proposta recebida lhe pareça tentadora: se conseguir passar três noites seguidas dentro do castelo assombrado, receberá a mão de uma bela princesa. Decide, por isso, tentar a sua sorte. Na primeira noite, três gatos ferozes tentam assustar o rapaz, mas sem quaisquer resultados. Nas duas noites seguintes, nem o fantasma, nem o horrível gigante conseguem amedrontá-lo. Demonstrou, assim, a sua valentia, casando com a princesa prometida. Neste caso, o número três aparece ligado ao amadurecimento do ser humano, relacionando-se com as três provas caracterizadoras dos contos de fadas: provas qualificadora, decisiva e glorificadora, depois das quais o herói atinge o amadurecimento e a felicidade. 


\section{2.- Em contos de Perrault}

Também o escritor francês recuperou imensos contos populares em que os números três e sete são uma constante, como veremos de seguida. Assim, na história «O pequeno Polegar», somos confrontados com um casal extremamente pobre que tem sete filhos. Aqui, está já patente a importância deste número, dado que remete para uma perfeição sonhada. Tudo no mundo é feito em ciclos de sete, de modo que este conto segue a lei universal. Apesar do filho mais jovem ser o mais pequeno e o mais frágil, não é por acaso que se assume como o herói. É o sétimo, o escolhido, marcado desde o nascimento para levar a cabo grandes feitos. Da mesma forma, o ogre em casa de quem os jovens pernoitam tem também sete filhas, continuando a insistir-se no caráter transcendente deste número. Deve referir-se que estas meninas não são mais do que o desdobramento do Polegar e de seus irmãos. É graças a elas que os meninos conseguem salvar-se. Eé de salientar, ainda, o cariz disfórico da morte das jovens: ao degolá-las sem querer, o ogre está já a traçar o seu destino. Não morre, mas perde os seus poderes, uma vez que destruiu a perfeição existente na sua própria casa. É, pois, lógico que o Polegar se apodere das botas de sete léguas e faça fortuna. Estas botas são, mais uma vez, um símbolo divino, dado que encurtam as distâncias, levando à ascensão de quem inicialmente era apresentado como fraco e pequeno. Uma grande lição para as crianças que percebem que mesmo os mais fracos podem vencer, porque haverá sempre algo ou alguém que os ajude durante a vida.

Já na «Gata Borralheira», deparamo-nos com a união de duas pessoas, em que existem filhos das relações anteriores. Assim, encontramos duas jovens, filhas da madrasta, às quais se soma Cinderela, que pode ser considerada a terceira e, por isso, é dotada das melhores qualidades. A sua perfeição é bastante mal vista pela malvada madrasta e pelas duas irmãs, cujas características as opõem à beleza e à bondade da Gata Borralheira. Nesta versão, Cinderela vai ao baile duas vezes, mas, noutras adaptações, a bela jovem desloca-se três noites seguidas ao palácio. Só ao terceiro dia perde a hora e foge, perdendo o seu sapatinho de cristal. Mais uma vez, o número três é sinónimo de perfeição e de limite temporal entre o propício e o adverso.

Também na narrativa «O Gato das Botas», estamos perante o símbolo da perfeição divina, uma vez que o moleiro tem três filhos e é o mais novo, à partida prejudicado pela partilha da herança paterna, que se tornará o herói da história. Na verdade, os irmãos mais velhos receberam, respetivamente, um moinho e um burro. Ao mais jovem, restou apenas um gato. Mesmo assim, decide confiar neste e na sorte, acabando por fazer fortuna. Além disso, o narrador faz referência indireta a diversas peripécias do senhor gato, mas são apenas três as vezes em que se expressa textualmente a ajuda do animal, durante o passeio com o rei. De facto, este intercede em dois campos agrícolas e, por fim, no palácio do gigante, demonstrando que se deve aceitar sempre ajuda, mesmo que pareça, à partida, insignificante. 


\section{3·3.- Em contos portugueses}

As histórias portuguesas são, também elas, ricas em simbologia numérica. Por essa razão, selecionamos alguns contos compilados por Teófilo Braga, em que encontramos símbolos direcionados para os já referidos significados dos números três e sete.

Assim, em «As três fadas», Santo António ofereceu três maçãs a uma pobre mulher que ansiava ter um filho. Ao comê-las, ela poderia conceber uma criança, de modo que verificamos já a presença do divino no número três. Mas a perfeição esperada é posta em causa pelo facto de ser o marido a comer as referidas maçãs e, por isso, padecer dos males da gravidez e abandonar a menina à nascença. Já crescida, e depois de se apaixonar por um príncipe, é atirada a um poço pela mãe do amado, sendo salva por três fadas, que a cobrem de dons dignos de uma princesa: "maior perfeição do mundo", "tesourinha de prata” e “palácio”. Está, de novo, demonstrado o caráter perfeito do número três, sempre presente neste tipo de história. Saliente-se, ainda, que só a terceira pessoa a procurar a jovem no seu palácio - o próprio príncipe - consegue lembrar-se de todo o recado e supera a proibição da mãe, sendo feliz com a amada. Vê-se, pois que, neste conto, está patente o desenvolvimento do ser humano: só depois de ser dotada com três dons e de receber três visitas, símbolos da maturação física e psíquica, a jovem e o príncipe serão felizes.

Já no conto «O mestre das artes», um homem tinha três filhos e, como já é habitual num conto deste género, o mais jovem era o mais inteligente, tendo a capacidade de se transformar naquilo que desejasse. Estamos, mais uma vez, perante a magia do número três, ligado ao sagrado e que leva a que o terceiro filho seja marcado, escolhido, desde a nascença, para realizar grandes coisas. Esta história pode ser dividida em duas fases, ambas imbuídas de simbologia, dado que em cada uma ocorrem três transformações. Assim, na primeira fase, o jovem tornou-se cão, cavalo e pássaro, para assegurar a fortuna da família e, simultaneamente, cuidar do seu desenvolvimento pessoal. Atente-se ao facto da terceira metamorfose lhe dar asas, ou seja, liberdade de ação e de pensamento. Na segunda fase, transforma-se em anel, em milho e em doninha, para colmatar a maturação já iniciada anteriormente, conseguindo, pois, matar o seu opositor e casar com a princesa.

Temos, depois, «A bicha de sete cabeças», em que estamos, de novo, direcionados para o número sete enquanto manifestação do transcendente e mesmo do fantástico. Remete, neste caso, para uma certa ambivalência, podendo ser relacionado com o mal: as sete cabeças pertencem a um monstro e só triunfando sobre ele o herói terá sucesso. A história começa com a partida do príncipe, em busca do seu amigo, filho do sapateiro, que tinha sido banido do reino. Depois de se encontrarem, salvam uma jovem donzela, por quem o príncipe se apaixona. Somando o número de companheiros, não é estranho verificar que temos como resultado o três. Do mesmo modo, dormiram num local onde se encontravam três cruzes e três pombas, ambos símbolos divinos, que remetem, respetivamente, para o calvário de Cristo e para a paz e sabedoria. Saliente-se, porém, a ambivalência das pombas: avisam de algo negativo que poderá acontecer, mas, ao mesmo tempo, 
ameaçam de morte aquele que ousar desvendar o segredo. O jovem sapateiro consegue vencer a bicha, mas é mal interpretado. Só ao sacrificar-se para contar a verdade leva a que o príncipe caia em si e, no final, vença a amizade.

Em «Cravo, rosa e jasmim», como em quase todos os contos maravilhosos, encontramos uma mulher com três filhas, o que remete já para um símbolo de beleza e totalidade. Mas esta perfeição é quebrada no momento em que cada uma das jovens desaparece, tentando tirar uma flor da água: um cravo, uma rosa e um jasmim, respetivamente. Mais tarde, um irmão, entretanto nascido, irá ter um papel preponderante na busca das irmãs. Saliente-se, ainda, o facto da irmã mais jovem pedir três dias, antes de aceitar casar-se com o monstro, numa clara alusão ao número três como limite entre o bem e o mal; neste caso, entre o casamento forçado e o salvamento, com a ajuda do irmão e dos cunhados.

Em «O cavalinho de sete cores», o título remete, desde já, para as simbologias estudadas, uma vez que as sete cores do arco-íris são uma das manifestações da beleza e perfeição deste número. Saliente-se que o referido cavalo era mágico, daí o seu nome se associar, por analogia, ao espectro solar e ao caráter sobrenatural do numeral em análise. Simultaneamente, surge o número três, na medida em que o rei mouro tinha três filhas, reenviando para a referida perfeição deste símbolo. Como diz a sabedoria popular «Três é a conta que Deus fez»! É, novamente, a mais jovem que tem parte ativa no desenrolar da ação.

Por fim, em «O matador de bichos», uma profecia leva uma princesa a ser encerrada numa torre, sendo anunciado que, durante sete anos, só poderia ser-lhe servida carne sem osso. Este tempo de penitência aproxima-se do intertexto bíblico, na medida em que Jacob trabalhou sete anos para casar com Raquel. Na verdade, só depois de mais sete anos consegue unir-se à amada, devido à fraude do sogro. Também na história em análise, a perfeição do número sete é quebrada, uma vez que um descuido leva a que o tempo de cárcere não seja cumprido e a que a jovem fuja com um duque. Tudo faria prever que ambos seriam felizes, mas, como o ciclo de amadurecimento não foi cumprido, seguiu-se a desgraça: perdeu o amado no rio e enfrentou diversas privações para criar o filho. Este irá mostrar-se muito corajoso, vencendo os sete bandidos, numa nova aproximação ao referido texto bíblico. Só aqui será concluído o ciclo de crescimento necessário para que o jovem e a sua mãe possam regressar ao palácio e serem, finalmente, felizes.

\section{Conclusão}

O conto, em geral, e o conto maravilhoso, em particular, aproximam-se do universo infantil, dado que têm por grandes funções divertir e ensinar, e que se adequa à criança através da sua linguagem mágica e simbólica.

Neste trabalho, procurámos demonstrar a importância dos números três e sete, em domínios da vida humana, incluindo nos contos maravilhosos. De facto, ficou bem clara a natureza divina destes símbolos, que reenviam para conceitos como a perfeição e a 
totalidade, e assumem um papel central na compreensão das nossas ações. Tanto a magia do número três como a plenitude do número sete influenciam profundamente o pensamento ocidental, sendo, por isso, natural a sua presença nas manifestações artísticas do povo, de onde provém os contos de fadas.

Finalmente, analisámos a ocorrência destes símbolos em contos maravilhosos estrangeiros e portugueses, podendo afirmar-se que a sua existência é quase sistemática. Na verdade, quase todas as histórias atribuídas, aos irmãos Grimm, a Perrault ou a Teófilo Braga, possuem um destes elementos, ou mesmo os dois conjugados. 


\section{Referências Bibliográficas}

- AAVV (1994). Os mais belos contos de fadas. Lisboa: Selecções Reader’s Digest.

- Bettelheim, B. (1998). Psicanálise dos Contos de Fadas. Lisboa: Bertrand.

- Chardonnens, A. (1990). Magie du Nombre Sept. Zurich:OSL.

- Chevalier, J. e Gheerbrant, A. (1998). Dictionnaire des symboles. Paris: Editions Robert Laffont

- Cordeiro, M. M. (tradução e adaptação) (s/d). Contos de Grimm. Rio de Mouro: Girassol Edições

- Duborgel, B. (s/d). Imaginário e Pedagogia. Lisboa: Instituto Piaget.

- Góes, L. P. (I99I). Introdução à Literatura Infanto-Juvenil. São Paulo: Pioneira

- Held, J. (i980). O imaginário no poder - As crianças e a Literatura Fantástica. São Paulo: Sumus.

- Jean, G. (1990). Le pouvoir des contes. Paris: Casterman.

- Khéde, S. S. (I990). Personagens da Literatura Infanto-juvenil. São Paulo: Ática.

- Meireles, C. (1984). Problemas da Literatura Infantil. Rio de Janeiro:Nova Fronteira.

- Mesquita, A. (2002). Pedagogias do Imaginário, Olhares sobre a Literatura infantil. Porto: Edições ASA.

- Morgado, Margarida e Pires, Natividade Carvalho (2OI2). «As lições interculturais de contos tradicionais “vertidos” em literatura infantil», in Alabe 5 [http://www.ual.es/alabe].

- Mousseau, J. e Moreau, P. F. (I984). Dicionário do Inconsciente. Lisboa/São Paulo: Verbo.

- Perrault, G. (200o). O Pequeno Polegar, www.virtualbooks.com.br consultado em Io de janeiro de $20 \mathrm{I2}$.

- Pires, Natividade (20IO). «O Terceiro na Literatura para Crianças: modelos de identificação», in Alabe 1 [http:/ /www.ual.es/alabe].

- Projecto Vercial (2002-2004). Literatura Portuguesa de Tradição Oral 
- Propp, V. (2000). Morfologia do Conto. Lisboa: Vega.

- Reis, C. e Lopes, A. C.M. (2002). Dicionário de Narratologia. Coimbra: Almedina.

- Rodari, G. (1993). Gramática da Fantasia - Introdução à arte de inventar histórias. Lisboa: Caminho.

- Simonsen, M. (1987). O Conto popular. São Paulo: Martins Fontes.

- Soares, M. L. C. (2003). Considerações gerais sobre a Literatura tradicional de transmissão oral: uma proposta de análise à versão portuguesa de «A Gata Borralheira». Vila Real: UTAD.

- Soveral, P. (2003). O Número Sete Cabalístico, www.psicopedagogia.com.br consultado em 6 de janeiro de 2012. 